\section{Influence of sodium nitroprusside on sperm motility, viability and morphology of frozen thawed buffalo semen}

\author{
DOMPLE VIJAY DIGAMBER ${ }^{1}$, K. LOGANATHASAMY, V. LEELA ${ }^{2}$ AND \\ P. KUMARASAMY ${ }^{3}$
}

\begin{abstract}
The present investigation has been undertaken to study the effects of exogenous supplementation of sodium nitroprusside (SNP), a nitric oxide (NO) donor on in vitro sperm characteristics of buffalo semen. Buffalo straws from 6 bulls were procured from Central Frozen Semen Production and Training Institute, Hesseraghatta, Banglore-51. The frozen straws were thawed at $37^{\circ} \mathrm{C}$ for 30 seconds and emptied into $15 \mathrm{ml}$ sterile plastic centrifuge tube containing $1 \mathrm{ml}$ of capacitation medium (control), addition of $100 \mu \mathrm{M} / \mathrm{ml}$ of SNP (SNP treatment I) and 100 $\mathrm{nM} / \mathrm{ml}$ of SNP (SNP treatment II) and were incubated at $37^{\circ} \mathrm{C}$ for 1 hour. After 1 hour incubation, the progressive motility was studied under bright field microscopy. Sperm motility was significantly $(\mathrm{P}<0.01)$ lowered in SNP treatment I $(11.67 \% \pm 1.67)$ and II $(23.33 \% \pm 2.11)$ as compared to control $(43.33 \% \pm 2.11)$. Between treatments, sperm motility was significantly $(\mathrm{P}<0.01)$ high in SNP treatment II than SNP treatment I. The sperm viability was assessed by the supravital Eosin and Nigrosin stain method. Significantly $(\mathrm{P}<0.01)$ higher percentage of spermatozoa were alive in control (56.67\% \pm 0.88$)$ in comparison with SNP treatment I (25.08\% $\pm 1.19)$ and II $(37.83 \% \pm 1.27)$. But,more spermatozoa were significantly $(\mathrm{P}<0.01)$ alive in SNP treatment II than SNP treatment I. The sperm morphology was determined by Rose Bengal stain technique. Morphologically normal spermatozoa were significantly $(\mathrm{P}<0.01)$ more in control $(83.00 \% \pm 0.62)$ when compared to SNP treatment I $(53.00 \% \pm 0.59)$ and II $(68.42 \% \pm 0.87)$. In similar way, significantly $(\mathrm{P}<0.01)$ higher proportions of spermatozoa were morphologically normal in SNP treatment II than SNP treatment I. From this study, it is concluded that addition of SNP, a NO donor has detrimental effects on the sperm motility, viability and morphology of frozen thawed buffalo semen on concentration dependant manner.
\end{abstract}

Key words : Sperm motility, viability, Morphology, Sodium nitroprusside, Buffalo semen

How to cite this paper : Digamber, Domple Vijay, Loganathasamy, K., Leela, V. and Kumarasamy, P. (2016). Influence of sodium nitroprusside on sperm motility, viability and morphology of frozen thawed buffalo semen. Vet. Sci. Res. J., 7(1) : 54-61.

Paper History : Received : 01.01.2016; Revised : 03.03.2016; Accepted : 25.03 .2016 